\title{
Life cycle cost analysis of energy efficiency design options for refrigerators in Brazil
}

\author{
Edson Adriano Vendrusculo • \\ Guilherme de Castilho Queiroz • \\ Gilberto De Martino Jannuzzi • \\ Herculano Xavier da Silva Júnior . \\ José Antenor Pomilio
}

Received: 3 October 2007 / Accepted: 17 November 2008 / Published online: 15 December 2008

(C) Springer Science + Business Media B.V. 2008

\begin{abstract}
The purpose of this paper was to present the results of a life cycle cost analysis concerning the purchase and operation of a more efficient popular refrigerator model compared with a baseline design in Brazil. The summarized results may be useful for organizations working to promote sustainable energy development. This paper specifically focuses on refrigerators, since their energy consumption is predicted to constitute over $30 \%$ of the total average domestic electricity bill in Brazilian households. If all new Brazilian refrigerators had an energy efficiency at
\end{abstract}

E. A. Vendrusculo $(\bowtie) \cdot J$. A. Pomilio

School of Electrical and Computer Engineering,

State University of Campinas,

Avenida Albert Einstein 400, PO box 6101,

13083-970 Campinas, São Paulo, Brazil

e-mail: adriano@dsce.fee.unicamp.br

G. d. C. Queiroz

Packaging Technology Center (CETEA),

Avenida Brasil 2880, Jardim Brasil,

13070-178 Campinas, Sao Paulo, Brazil

G. D. M. Jannuzzi $\cdot$ H. X. da Silva Júnior

School of Mechanical Engineering,

State University of Campinas,

Rua Mendeielev s/n,

13083-970 Campinas, São Paulo, Brazil

G. D. M. Jannuzzi

International Energy Initiative-Latin American Office,

PO box 6163, 13083970 Campinas, São Paulo, Brazil the level consistent with the least life cycle cost of ownership, it would result in an annual savings of 2.8 billion dollars (US\$) in electricity bills, $45 \mathrm{TWh}$ of electricity demand, and $18 \mathrm{Mt}$ of $\mathrm{CO}_{2}$ emissions, with a respective payback period of 7 years which is less than half the average estimated lifetime of a refrigerator. The analysis was conducted following the guidelines of similar analyses available from the US Department of Energy and the Collaborative Labeling and Appliance Standards Program.

Keywords Electrical consumption ·

Energy efficiency · Household refrigerator .

Life cycle cost analysis $\cdot$ Minimum energy performance standards $\cdot$ Payback period

\section{Introduction}

In the year 2001, the Brazilian National Congress approved the "National Energy Conservation Policy and Rational Use of Energy" law that requires minimum energy efficiency standards for energy-consuming equipment commercialized in Brazil (Brazilian law no. 10.295 2001). A first comparative analysis indicates great opportunities for energy savings with refrigerators. For example, some Brazilian models consume approximately $46 \%$ more energy than similar models being commercialized in Europe (ENERGY +2002; 
PROCEL 2002a). The models compared ${ }^{1}$ are the same type of appliance belonging to the one-star category (R4 category), which defines temperature of the frozen food compartment to be $\leq 6^{\circ} \mathrm{C}$ in accordance with specifications, found in Table 2, of the commission directive 2003/66/EC published by the official journal of the European Union (CLASP 2003).

Energy efficiency methodologies made accessible by the US Department of Energy (DOE) and Collaborative Labeling Standard Program (CLASP) were used in the following analysis. An engineering analysis was used to determine the range of potential energy efficiency improvements and their costs. This analysis considers new designs or combinations of designs and technologies that are not commercially available and can, therefore, result in products with higher efficiencies than those available on the market at this time.

The statistical analysis of a set of energy use data for one-star refrigerator models available in Brazil in 2004 was used to establish a study scenario in this paper. For each model, energy use is plotted as a function of adjusted volume. Adjusted volume (AV) accounts for the different temperatures in the fresh food and freezer compartments of refrigerators, refrigerator freezers, and freezers.

To analyze the economic impact of potential efficiency improvements on consumers, the consumer payback period and life cycle cost (LCC) have been used. Analyses of payback periods and LCCs illustrate the trade-off and help identify policies that will have net benefits for consumers.

Many inputs are needed for economic analyses of quantities, such as LCC and payback period. For example, to calculate LCC, several pieces of data are needed, including the incremental purchase price for the more efficient product, energy savings, fuel price, appliance lifetime, and consumer discount rate. To calculate the payback period, only the first three terms are needed (Wiel and McMahon 2001).

However, like other developing countries, it is also difficult to get complete statistical and technical data for analysis. Therefore, a different scenario building methodology was used. The authors have also provided a brief appendix containing the results of statistical and LCC

\footnotetext{
${ }^{1}$ The European and Brazilian models that have been used for comparison purposes have similar refrigeration system, same sizes, and are even the same brand. The major discrepancy is only the total gross capacity, i.e., 2551 in the European and 2401 in the Brazilian model.
}

analysis for refrigerators in the European Union and USA, which served as reference material. Appendix 1 refers to the guidebook provided by CLASP, as it was available at the time of this paper's writing. However, nowadays, a revised version (the "COLD II" study) is available and should be preferred for future studies of energy labeling and minimum energy efficiency standards for domestic refrigeration appliances.

Cost-effective technical improvements (or design options) were considered in the analysis and their energy, economic, and environmental impacts through the LCC approach were evaluated. Simulation results allowed estimates of the impacts on consumers, manufacturers, and the environment over a long-term period of up to 16 years (2005 to 2020), starting from the moment of adoption of more efficient refrigerators. The present study analyzes the opportunities of establishing minimum energy performance standards (MEPS) for the class of "popular" refrigerators sold in Brazil. These are very simple domestic appliances having only basic technical elements; therefore, a brief technical description is presented below.

\section{Target refrigerator technology overview}

Brazilian popular refrigerators consist of a one-door cabinet with a small self-contained freezer compartment, as illustrated in Fig. 1. A single vapor compression

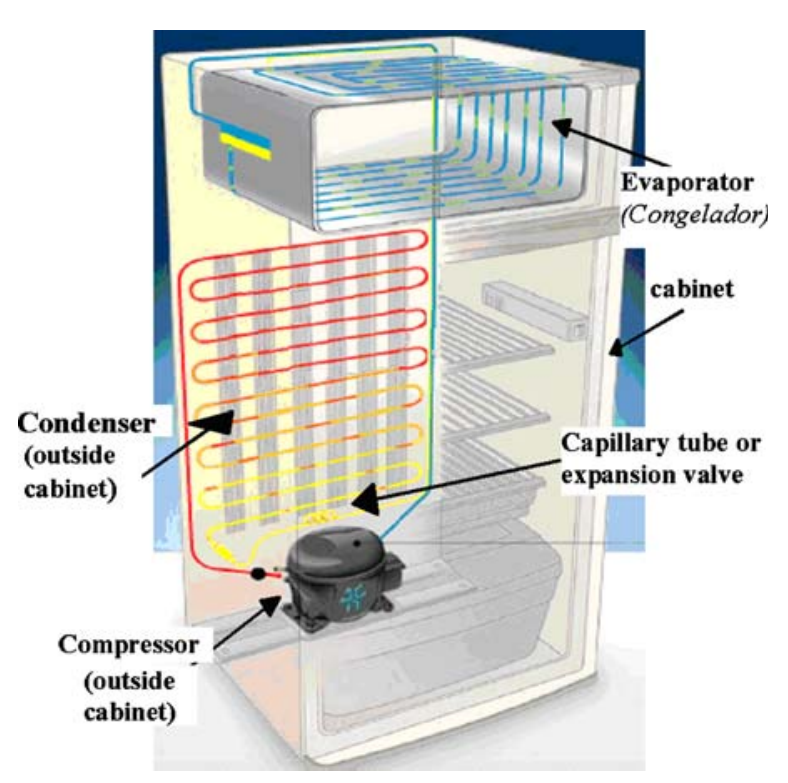

Fig. 1 One-door refrigerator (Embraco 2002) 
cycle that operates at the freezer evaporating saturation temperature provides refrigeration for both the fresh food and freezer compartments. The refrigeration circuit comprises four simple elements: a compressor, capillary tube (expansion valve), an evaporator, and a condenser. The distribution of cool air within the cabinet is via natural convection from the evaporator, meaning that there is no fan to distribute air within the cabinet. In general, most of these simple models do not have complex controls or accessories.

The one-door household refrigerator belongs to the one-star classification according to Technical Standard (ISO 7371 1995). In compliance with the standards, it is designed to maintain an internal temperature of $5^{\circ} \mathrm{C}$ within the fresh food compartment and $-6^{\circ} \mathrm{C}$ within the frozen food compartment. A thermostat located at the evaporator, which switches the compressor on and off, provides the temperature control in the cooling process. For this study, the most commonly sold refrigerator in the Brazilian market was used as the reference for the technical and economical analysis. The baseline refrigerator has a total gross capacity of 3301 and has an average 311 of net volume within the frozen food compartment. ${ }^{2}$

\section{Energy efficiency standards in Brazil}

Brazil has introduced voluntary efficiency labels for refrigerators and other appliances since the late 1980s. These labels have been developed via a process of consensus arrangement between the government and manufacturers. More recently, the "National Energy Conservation Policy and Rational Use of Energy" law (Brazilian law no. 10.295 2001) was established under supervision of the Ministry of Mines and Energy, which leads a steering committee (CGIEE) composed of seven members, made up of representatives of the Ministry of Science and Technology, Ministry of Development, Industry and External Commerce, National Agency of Electrical Energy, National Agency of Petroleum, Brazilian universities, and Brazilian

\footnotetext{
${ }^{2}$ Some physical dimensions of the base case are 1,528-mm height, 619-mm width, and 691-mm depth. A hermetic compressor is used, which has a cooling capacity of $425 \mathrm{Btu} / \mathrm{h}(125 \mathrm{~W})$, a displacement of $4.23 \mathrm{cc} / \mathrm{rev}$, and an energy efficiency rate of $1.07 \mathrm{kcal} / \mathrm{Wh}$, assembled for low back pressure applications. The electrical specification comprises an operating voltage range of $90-140 \mathrm{~V}$ supplied by a single-phase $60-\mathrm{Hz}$ grid.
}

citizens, in order to set new mandatory efficiency standards. The public National Institute of Metrology, Standards, and Industry Quality (INMETRO) inspects the laboratories that are certified to measure the energy consumption of households, such as refrigerators, and the National Energy Conservation Program (PRO$\mathrm{CEL}^{3}$ ) supports the steering committee (CGIEE), provides information, and helps people to find the most efficient energy appliance (PROCEL 2002b).

As of 2005, only electrical motors were subject to mandatory minimum energy efficiency standards. Information to consumers on the energy consumption of household refrigerators is provided through two labels displayed on refrigerators available on the retail market: a comparative energy information label (energy rating label) and an endorsement label. Figure 2 shows both Brazilian energy efficiency information and endorsement labels. The former follows the appearance of the European energy label design and shows the comparative energy efficiency class of the appliance on a scale rated from $A$ to $G$, where $A$ is for the best performing appliances. Note that the formula used to delineate the energy label class are not the same in the Brazilian and EU labeling schemes nor are the test procedures identical, as Brazilian appliances are tested at an ambient temperature of $32^{\circ} \mathrm{C}$ as compared to $25^{\circ} \mathrm{C}$ in Europe. Appliances that reach a class A level, according to INMETRO, may be awarded with the PROCEL's endorsement label, shown in Fig. 2 b.

A technical committee, led by a representative of PROCEL and seven representatives of several technical associations, decides which manufacturer will receive the label. The following are the technical associations involved: Electrical Energy Research Center (CEPEL), INMETRO, Customer Support National Institute (IDEC), Brazilian Electrical and Electronic Industry Association (ABINEE), National Association for Electro-electronic Products Industries (ELETROS), Brazilian Association of Manufacturers of Refrigeration, Heating, Air Conditioning and

\footnotetext{
${ }^{3}$ PROCEL operates by funding or co-funding energy efficiency projects, such as, research and development (R\&D), education and training, testing, labeling, standards, demonstration, and others. The program works on both increasing end-use efficiency and reducing losses in electricity generation, transmission, and distribution systems, though the latter diminished greatly after the liberalizing reforms of the 1990s. PROCEL cooperates with state and local utilities, state agencies, private companies, universities, and research institutes.
} 
a

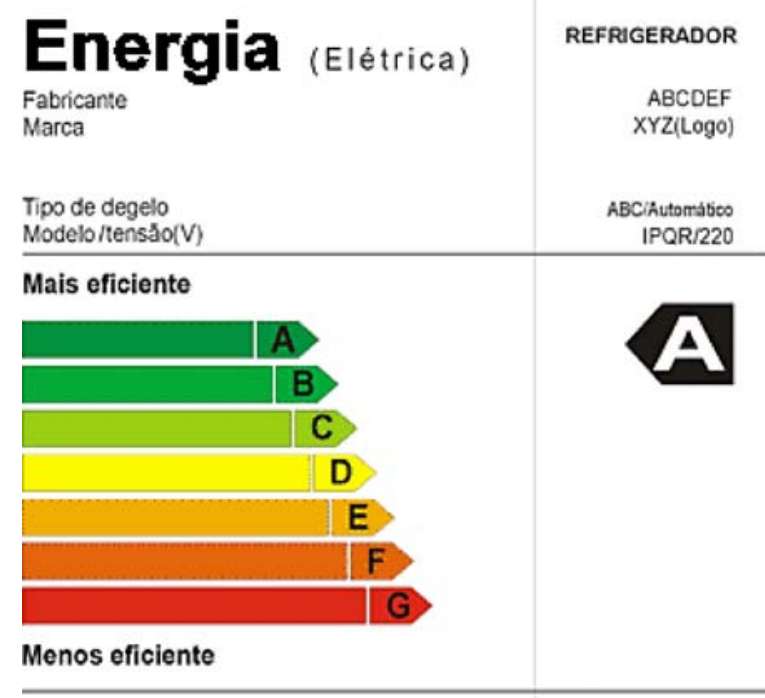

\begin{tabular}{|c|c|}
\hline CONSUMO DE ENERGIA (kWh/mes) & \\
\hline Volume do compartimento refrigerado $(\ell)$ & 000 \\
\hline Volume do compartimento do congelador $(f)$ & 000 \\
\hline Temperatura do congelador $\left({ }^{\circ} \mathrm{C}\right)$ & Pים 18 \\
\hline
\end{tabular}

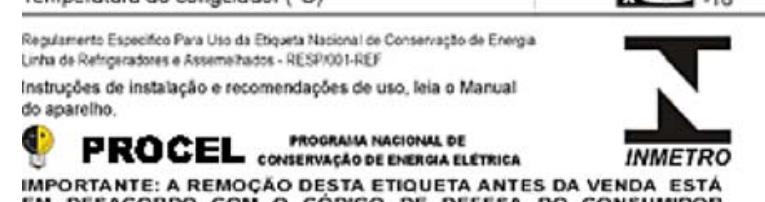
IMPORTANTE: A REMOCAO DESTA ETIQUETA ANTES DA VENDA ESTA
EM DESACORDO COM O CODIGO DE DEFESA DO CONSUMIDOR

b

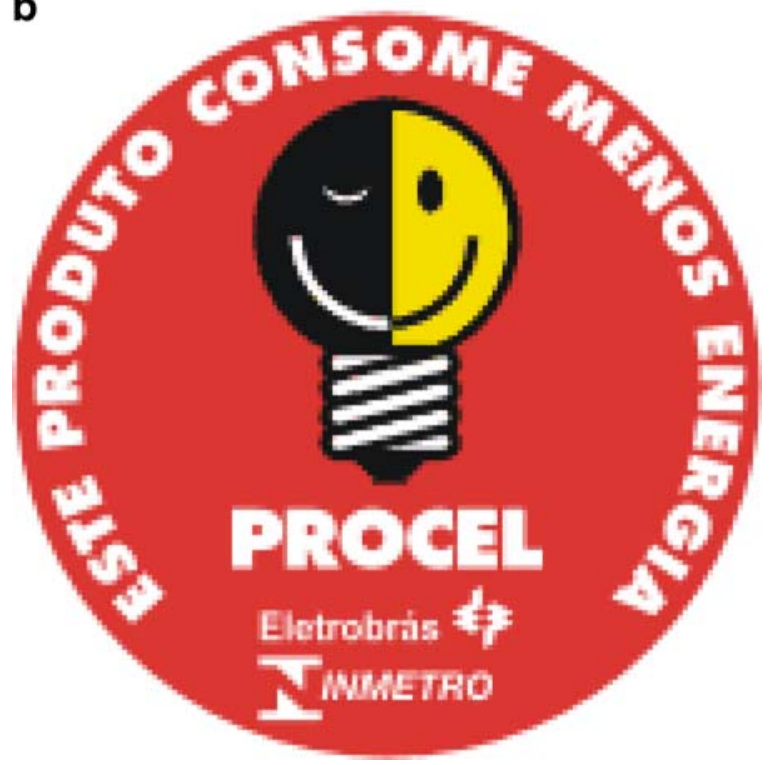

Fig. 2 Brazilian labels (PROCEL 2002b)
Ventilation Equipment (ABRAVA), and Brazilian Lighting Industry Association (ABILUX).

The endorsement label is displayed exclusively on the most efficient appliance and, in order to carry this label, the appliance's manufacturer is required to be approved in an eventual audit done by a labeling inspection committee. This committee chooses a sample taken directly from the refrigerator production line to be tested in a certified laboratory. The inspection committee has representatives from the associations INMETRO and PROCEL, as well as from the certified laboratory.

\section{Electrical consumption of appliances in Brazil}

In 2003, Brazil consumed approximately $325 \mathrm{TWh}$ of electrical energy, of which $46 \%$ was used by the industrial sector and about $27 \%$ was consumed by the residential sector (BEN 2004). Figure 3 shows the estimated share of household electricity consumption by appliance types (Chade 2004).

As seen in Fig. 3, refrigerator electricity consumption represents a large share in all surveyed houses. As a consequence, the refrigerator was preferred by PROCEL and INMETRO to establish the energy conservation standards. Table 1 shows the refrigerator features taken into account by the INMETRO labeling program (INMETRO 2002). Each model is analyzed according to its $\mathrm{AV}$, where the label class $\mathrm{A}$ is awarded to the more energy-efficient equipment using a formula established by INMETRO. A technical committee, composed of representatives from industry and government, uses a statistical analysis to define this index. INMETRO sets up the maximum allowable

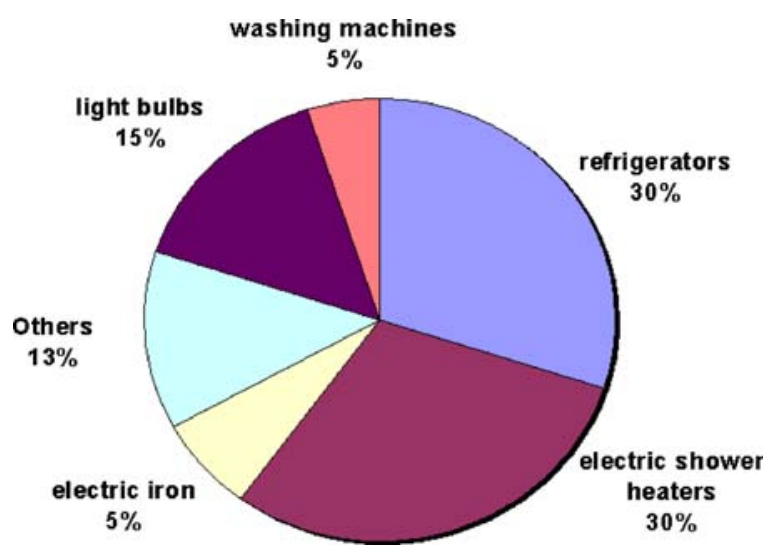

Fig. 3 End-use electricity consumption in Brazilian households 
Table 1 Refrigerator features account to the INMETRO/PROCEL labeling program

\begin{tabular}{|c|c|c|c|c|c|c|}
\hline \multirow[t]{2}{*}{ Brand } & \multirow[t]{2}{*}{ Model } & \multicolumn{3}{|l|}{ Volume } & \multirow{2}{*}{$\begin{array}{l}\text { Consumption } \\
\text { (kWh/month) }\end{array}$} & \multirow{2}{*}{$\begin{array}{l}\text { INMETRO } \\
\text { label }\end{array}$} \\
\hline & & $\begin{array}{l}\text { Fresh food } \\
\text { compartment }\end{array}$ & $\begin{array}{l}\text { Small freezer } \\
\text { compartment }\end{array}$ & $\begin{array}{l}\text { Adjusted } \\
\text { volume }^{a}(A V)\end{array}$ & & \\
\hline $\mathrm{BOSCH}$ & RB 31 & 297 & 00 & 297 & 24.5 & A \\
\hline $\mathrm{BOSCH}$ & RB 38 & 367 & 00 & 367 & 27.0 & A \\
\hline BRASTEMP & BRA31A & 253 & 33 & 300 & 32.0 & $\mathrm{C}$ \\
\hline BRASTEMP & BRA35A & 296 & 33 & 343 & 36.0 & $\mathrm{C}$ \\
\hline BRASTEMP & BRB35A & 329 & 00 & 329 & 36.5 & $\mathrm{D}$ \\
\hline BRASTEMP & BRF36A & 330 & 00 & 330 & 29.5 & A \\
\hline $\mathrm{CCE}$ & R31L & 263 & 30 & 306 & 30.0 & B \\
\hline $\mathrm{CCE}$ & R32SL & 268 & 30 & 311 & 30.0 & $\mathrm{~B}$ \\
\hline $\mathrm{CCE}$ & $\mathrm{R} 26 \mathrm{~L}$ & 224 & 30 & 267 & 32.0 & $\mathrm{D}$ \\
\hline BLUE SKY & $\mathrm{R} 31 \mathrm{~L}$ & 263 & 30 & 306 & 30.0 & $\mathrm{~B}$ \\
\hline HOUSTON & $\mathrm{R} 31 \mathrm{~L}$ & 263 & 30 & 306 & 30.0 & B \\
\hline CONSUL & CRB23B & 223 & 00 & 223 & 32.0 & $\mathrm{~F}$ \\
\hline CONSUL & CRC24B & 191 & 22 & 222 & 30.5 & $\mathrm{~F}$ \\
\hline CONSUL & CRA32A & 272 & 31 & 316 & 26.6 & A \\
\hline CONSUL & CRA32B & 272 & 30 & 315 & 24.9 & A \\
\hline CONSUL & CRC32A & 272 & 31 & 316 & 28.8 & A \\
\hline CONSUL & CRA36A & 312 & 30 & 355 & 31.5 & A \\
\hline CONTINENTAL & RC 27 & 223 & 29 & 264 & 23.7 & A \\
\hline CONTINENTAL & $\mathrm{RC} 30$ & 257 & 29 & 298 & 27.0 & A \\
\hline CONTINENTAL & RC 37 & 324 & 33 & 371 & 33.0 & A \\
\hline ELECTROLUX & $\mathrm{R} 250$ & 214 & 26 & 251 & 24.6 & $\mathrm{~B}$ \\
\hline ELECTROLUX & $\mathrm{R} 280$ & 237 & 26 & 274 & 25.0 & A \\
\hline ELECTROLUX & R310 & 263 & 31 & 307 & 30.0 & B \\
\hline ELECTROLUX & R330 & 286 & 31 & 330 & 30.2 & A \\
\hline ELECTROLUX & R360 & 312 & 31 & 356 & 32.4 & A \\
\hline ESMALTEC & RG3100E & 283 & 27 & 321 & 34.8 & B \\
\hline GE & GE310A & 263 & 31 & 307 & 30.0 & $\mathrm{~B}$ \\
\hline
\end{tabular}

${ }^{\mathrm{a}} \mathrm{AV}=$ fresh compartment +1.42 small freezer compartment

energy consumption per label class as a function of the adjusted volume, as is done in most other countries applying mandatory refrigerator standards and labeling schemes. The adjusted volume accounts for the different temperatures in the fresh food and freezer compartments of the refrigerator. In Brazil, the temperature and relative humidity are respectively set to $32^{\circ} \mathrm{C}$ and $50 \%$ according to the standardized test methods. Brazilian refrigerators are classified as Tropical (climate class T) appliances.

\section{Scenario building methodology}

The analysis hereafter takes into account a hypothetical scenario based on the market share of Brazilian manufacturers. The leading brand manufacturer had $53 \%$ of the wholesale refrigerator market in 2002 and his prod- ucts were technologically more advanced compared to the other models on the market. The second largest refrigerator manufacturer had $29 \%$ of the market, but his product had a lower energy performance as compared to the market leader. Thus, the second manufacturer allows for more improvements to be targeted. Lastly, the remaining manufacturers shared the outstanding $18 \%$ of the wholesale market (Datamark 2002).

The authors emphasize that they had no data available for one specific refrigerator model, listed in Table 1. Thus, the market share percentage in the last paragraph refers to all refrigerator models belonging to a brand owner (e.g., market share is $53 \%$ for sales of all models CRA23, CRA24, CRA32, and CRA36 in Table 1).

This study estimates an "average refrigerator model" so that the analysis for the Brazilian market could be performed. This model results from weighted 
averages of retail market parameters of the two chosen refrigerators, respectively indicated as X and Y in Fig. 4, which shows the linear regression of the consumption for data in Table 1. The weights chosen corresponded to the $53 \%$ of market share for the most sold refrigerator (X), and the remaining $47 \%$ was taken as the weight for the second model (Y). For simplicity purposes, this arrangement essentially takes into account two brands, which by far hold the highest share of the market, while other brands have minor market share percentages. These two brands have an adjusted volume of 316 liters $(319.2 \mathrm{kWh} /$ year) and 3301 (354 kWh/year) as indicated in Fig. 4, respectively. Therefore, the energy consumption for the "average refrigerator model" is given by:

$$
\begin{aligned}
\mathrm{EC}_{\text {wavg }} & =0.53 \times X_{\text {cption }}+0.47 \times Y_{\text {cption }} \\
& =335.5[\mathrm{kWh} / \text { year }]
\end{aligned}
$$

where, $X_{\text {cption }}$ and $Y_{\text {cption }}$ are the energy consumption for $\mathrm{X}$ and $\mathrm{Y}$ models, respectively.

Based on the aforementioned considerations, the effort is applied hereafter to assess this scenario.

\section{Energy consumption resulting from technical improvements}

Design options (or technical improvements) represent changes in the design of a baseline model that improve its efficiency. Several technical improvements may be applied in order to reduce the energy consumption of refrigerators, but laboratory facilities and time limited the number of improvements that could be simulated in this study. Simulations of improved designs were conducted using the ERA ${ }^{4}$ software tools (E.P.A. Refrigeration Analysis) distributed by the US

\footnotetext{
${ }^{4}$ The validation of the ERA refrigerator model (one door) was done by comparing the electricity consumption of $28.14 \mathrm{kWh} / \mathrm{month}$ obtained from ERA with the consumption of $28.1 \mathrm{kWh} / \mathrm{month}$ declared by the refrigerator manufacturer. As seen, the error for electricity consumption from simulation and manufacturer was within $1 \%$. An experimental test in a specialized laboratory was also carried out in accordance with the ISO7371 test procedures and the measured consumption was with $28.35 \mathrm{kWh} /$ month. The technical input data table for ERA is based on overall information about the cabinet and the main elements' dimensions such as, evaporator and condenser. Specific data on characteristics of materials, insulation thermal resistivities, in addition to internal temperatures and refrigeration cycle information, were also necessary.
}

Environmental Protection Agency (Merriam et al. 2002). The results of the technical improvement simulations, shown in Table 2, consider two major groups of improved designs: those using more efficient compressors and those derived from an increase of insulation thickness. Simulations were carried out for both brands, $\mathrm{X}$ and $\mathrm{Y}$, and then the results were weighted, taking into account the respective market share, as shown in Eq. 1, to get the final energy efficiency.

A new compressor with about $20 \%$ higher efficiency was used instead of the original. The compressor efficiency is declared in the compressor datasheet through the EER (energy efficiency ratio) acronym. This technical option is self-explanatory, since the more efficient compressor had EER=1.49 W/W comparative to $1.22 \mathrm{~W} / \mathrm{W}$ of the original in the baseline refrigerator.

Alternatively, the insulation thickness was increased for both refrigerator door and wall. Between $75 \%$ and $90 \%$ of the energy required by refrigeration unit may be attributed to the thermal performance of the insulated shell. Hence, by improving the performance of the shell, significant savings are possible. A common way of improving the overall thermal resistance of the shell is to increase its thickness. Adding from 1.27 to $2.54 \mathrm{~cm}$ ( 0.5 to $1.0 \mathrm{in}$.) of extra insulation results in an energy savings range from a few percent to over $10 \%$ relative to the previous design level (Hakim and Turiel 2002). Furthermore, results using modern compressors are also very impressive. As such, the set of all design options may expect savings of $44 \%$, as shown in Table 2 . In fact, it is a primary test, since material improvements and electronically commuted motor (including permanent magnet rotor) advances have pushed up the overall compressor efficiency very rapidly.

\section{Analytical elements of the standards setting process}

This section applies the life cycle cost analysis (LCCA) to consider the ambition and impacts of prospective energy efficiency standards. The LCCA performed comprised an engineering analysis (which analyzes potential technical improvements), a LCC, and a payback period analysis.

These analyses were performed in accordance with CLASP recommendations; hence, gathering data was 
Fig. 4 Linear regression

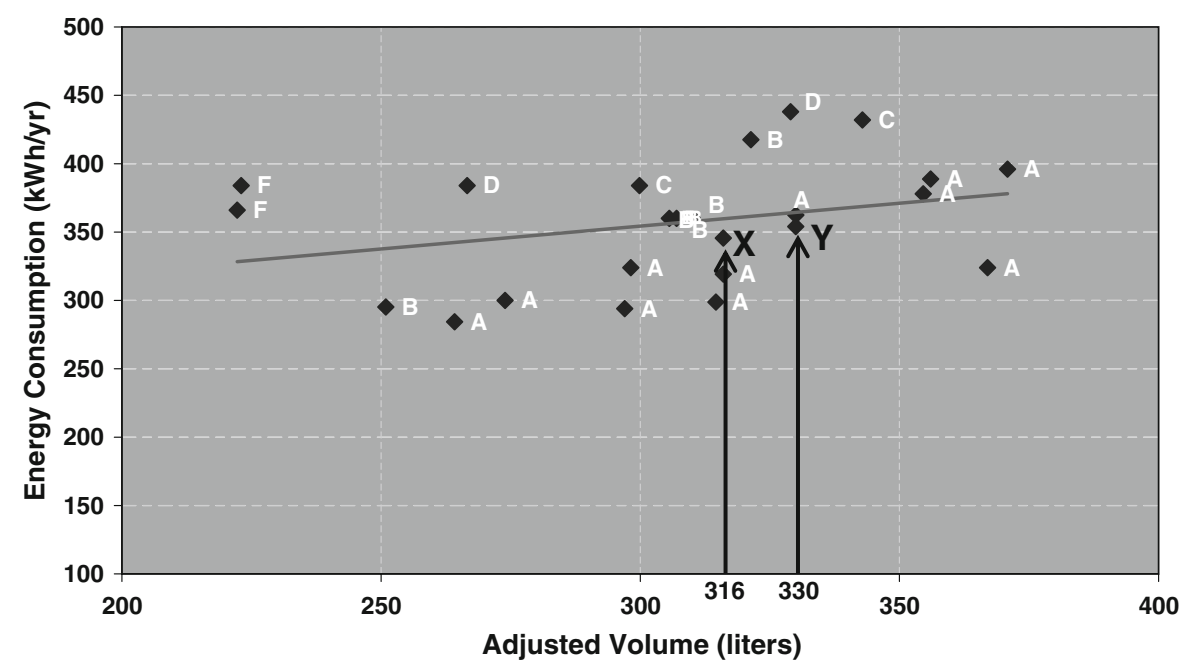

the main constraint. Therefore, underlying assumptions and approximations are highlighted along with its use hereafter.

\section{Engineering analysis}

Technical improvements, listed in Table 2, and their respective results were used to formulate hypothetical energy efficiency standards. Various approaches were considered for evaluating the feasibility of energy standards. The first approach considers the case where all existing refrigerator markets in 2001, referring to models in Table 1, are required to conform to a mandatory standard determined by the reference line $\mathrm{C} 0$, shown in Fig. 5. Such an approach implies that all refrigerators should be improved according to the regression line $\mathrm{C} 0$, expressed as follows:

$$
\mathrm{C}_{\text {cption }}=254.0+0.33 \times \mathrm{AV}[\mathrm{kWh} / \text { year }]
$$

where $\mathrm{C}_{\text {cption }}$ is the energy consumption.
In this case, which only considers a change in average energy use of those refrigerator models above the $\mathrm{C} 0$ line, it was found that market average refrigerator energy consumption might be reduced by $4 \%$ overall. Note that it was assumed that all models had equal sales, as the true market share data were not available.

Once all models in the market were imagined to satisfy the "C0 standard" line, new simulations were performed considering innovation $\mathrm{C} 1$ (Table 2), and the resulting data points were used to derive the new regression line $\mathrm{C} 1$, shown in Fig. 5. Based on this new situation, an estimated energy saving of $16.1 \%$ is obtained (see Table 2).

This procedure was repeatedly applied to define additional hypothetical standards $\mathrm{C} 2$ to $\mathrm{C} 5$, and their respective associated energy savings are listed in Table 2.

Each time increased efficiency standards are proposed, it is essential to assess the potential consumer, national industry, and environmental impacts that they would subsequently be expected to produce.

Table 2 Simulation results (Vendrusculo et al. 2003): one-door refrigerator energy efficiency

\begin{tabular}{|c|c|c|c|c|}
\hline \multirow[t]{3}{*}{ Technical improvements } & & \multicolumn{3}{|c|}{ Percent energy efficiency increase } \\
\hline & & \multicolumn{2}{|c|}{ Refrigerator } & \multirow{2}{*}{$\begin{array}{l}\text { Assumed scenario } \\
\text { Weighted average energy efficiency increase }(\%)\end{array}$} \\
\hline & & $X(\%)$ & $\mathrm{Y}(\%)$ & \\
\hline Compressor & $\mathrm{C} 1-$ more efficient $\mathrm{EER}=1.49 \mathrm{~W} / \mathrm{W}$ & 12.1 & 20.7 & 16.1 \\
\hline \multirow[t]{4}{*}{ Insulation thickness increase } & $\mathrm{C} 2$ - at door $=1 / 2 \mathrm{in.}$ & 3.9 & 3.8 & 3.9 \\
\hline & $\mathrm{C} 3$ - at wall $=1 / 2 \mathrm{in}$. & 10.2 & 14.1 & 12.0 \\
\hline & $\mathrm{C} 4-$ at door $=1$ in. & 2.9 & 2.9 & 2.9 \\
\hline & $\mathrm{C} 5$ - at wall $=1 \mathrm{in.}$ & 8.4 & 10.0 & 9.2 \\
\hline
\end{tabular}


Fig. 5 Application of an engineering approach to setting standards for Brazilian refrigerators

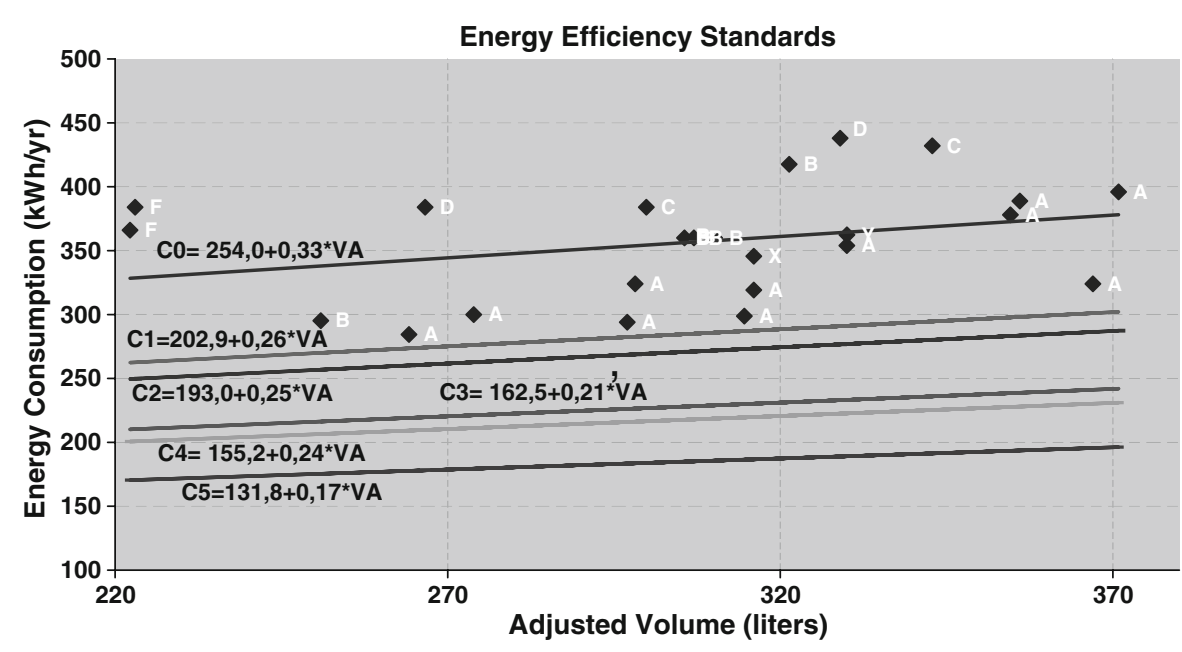

\section{Life cycle cost}

The LCC analysis takes into account the lifetime of the appliance and the consumer discount rate. LCC is the total consumer expense over the lifetime of the appliance, including purchase expense and operating costs (also including energy expenditures). Future operating costs are discounted to the time of purchase and summed over the lifetime of the appliance. LCC is expressed in Eq. 3 as a function of the retail price $(P)$, annual operating cost $\left(O_{\mathrm{t}}\right)$, lifetime $(N)$ in years, and the discount rate $(r$; Wiel and McMahon 2001; Biermayer 2001):

$\mathrm{LCC}=P+\sum_{t=1}^{N} \frac{O_{t}}{(1+r)^{t}}$

where $\sum_{t=1}^{N}$ means the sum over the lifetime, from year 1 to year $N$, where $N=$ lifetime of appliance (years) and $t$ is the year for which operating cost is being determined.

Equation 3 shows two main inputs to the LCC analysis: the appliance retail price $(P)$ and the appliance operating cost $(O)$. To set the final retail (selling) price of a more energy-efficient refrigerator, the cost of each design option, incorporated in the commercial equipment, is added to the baseline retail price.

The increase in manufacturing costs associated with each design change was estimated based on the Technical Support Document: Energy Efficiency Standards (US Department of Energy) for refrigerators, refrigerators-freezers, and freezers (DOE 1995).

It is very important to clarify that in Brazil, the appliance manufacturers evaluate design options and estimate developing cost with no commitment to the appliance standards steering committee and also there are no tax incentives for advanced energy-saving technologies. As a consequence, it is not a trivial issue to get data from manufacturers ${ }^{5}$ about the aforementioned refrigerator design options (i.e., manufacturing cost, efficiency gain) to proceed with the LCC calculations.

The cost of each more efficient design option, which includes the overall markup, is shown in Table 3. The percentage by which the sales price exceeds the manufacturer's cost of the equipment is the overall markup, which comprised the manufacturer markup, distributor or wholesaler markup, dealer markup, and sales tax (local and state governments apply sales taxes to refrigerator purchases). In this study, an overall markup of 2.42 was used based on information gathered by the authors from retailers and one manufacturer. A Brazilian appliance manufacturer supplied the manufacturer's cost of his baseline model and the retail price was derived from a survey of the Brazilian commercial actors. The purpose of the survey was to find out the average retail price of the baseline model. The "average refrigerator" used in the study had a retail price of $\mathrm{R} \$ 699.00$ (US\$ 211.81) which yielded a baseline manufacturing cost of $\mathrm{R} \$ 288.81$ (US\$87.52).

In view of the fact that no data was available from appliance manufacturers and component suppliers,

\footnotetext{
${ }^{5}$ Tax incentives for these technologies could encourage manufacturers to introduce new products and stimulate them to convey technical data for the appliance standards steering committee.
} 
Table 3 Expected incremental costs in the refrigerator retail price of each design option

\begin{tabular}{lc}
\hline Design option & Expected cost R\$ (US\$) \\
\hline C1 & $60(18.18)$ \\
C2 & $20(6.06)$ \\
C3 & $67(20.3)$ \\
C4 & $18(5.45)$ \\
C5 & $16.06(53)$ \\
\hline
\end{tabular}

estimates of technical improvement costs in Table 3 were extrapolated from the Department of Energy report Technical Support Document: Energy Efficiency Standards for consumer products: refrigerators, refrigerators-freezers, and freezers (DOE 1995). The exchange rate of 3.3 was applied in conversion to local currency $(\mathrm{R} \$=$ reals), i.e., $\mathrm{US} \$ 1.00=\mathrm{R} \$ 3.30$.

The operating cost in Eq. 3 is the sum of the energy cost and repair cost. The primary inputs for establishing the energy cost are the annual energy consumption and the average electricity price. The scenario assumed yielded an annual energy consumption of $338.80 \mathrm{kWh} /$ year through Eq. 1. The average electricity price is the mean price paid for all electricity, which at the time of this study was $\mathrm{R} \$ 0.252 / \mathrm{kWh}$ (US\$0.0763/kWh; ANEEL 2002a). Also, an average value of $18 \%$ for all state and federal tax charged in the electricity price was taken into account. This tax is considered constant over time for the analysis performed in this work. The repair cost is the cost to the consumer for replacing or repairing components that have failed in the equipment. However, it was assumed that no repair work is done throughout lifetime. Furthermore, it was assumed that operating cost is constant over time. As a result, the expression for LCC in Eq. 3 reduces to:

$\mathrm{LCC}=P+\mathrm{PWF} \times O_{t}$

where the present worth factor (PWF) is:

$\mathrm{PWF}=\sum_{t=1}^{N} \frac{1}{(1+r)^{t}}=\frac{1}{r}\left[1-\frac{1}{(1+r)^{N}}\right]$.

The discount rate is the rate at which future expenditures are discounted to establish their present value (ANEEL 2002a). The nominal discount rate $r=14 \%$ was assumed as recommended by the Brazilian Electricity Regulatory Agency (ANEEL). In Brazil, the overall electrical energy market is under ANEEL regulations. The minimum recommended to make a profit on energy efficiency programs is $12 \%$ (ANEEL 2002b). Note that compared to international practice, this figure is very high; however, discount rates even as high as $15.25 \%$ per year (inflation of $4.5 \%$ per year) have been recently practiced in Brazil (3CEE Report 2006). The expected return on investment in a more energy-efficient equipment can be asserted through the analysis of payback period.

Payback period (PAY)

The economic impact on consumers resulting from the potential efficiency improvements can be analyzed through a payback analysis approach. For example, for the target standard $\mathrm{C} 1$ in Fig. 5, the amount of time needed to recover the additional consumer investment on purchasing an efficient model through the lower operating costs is the payback period.

Data on the incremental purchase price for the more efficient product $(\Delta P)$, energy savings, and electricity price is required for the calculation of the payback. Equation 6 summarizes the payback (Wiel and McMahon 2001; Biermayer 2001):

$\Delta P+\sum_{1}^{\mathrm{PAY}} \Delta O_{t}=0$

where $\Delta O_{\mathrm{t}}$ is the variation in operating costs. However, operating costs were considered constant over time $t$ so that Eq. 7 could be applied:

$\mathrm{PAY}=-\frac{\Delta P}{\Delta O}$

\section{LCCA results}

The hypothetical MEPS levels derived from the LCCA analyses are highlighted in Fig. 6, which depicts the results according to the consumer's perspective. The LCC analysis suggests that setting MEPS at the C2 level will result in models that are $24 \%$ more efficient and have an average energy consumption of $266 \mathrm{kWh} /$ year, as shown in Table 2. As a consequence, respective increases of $3.7 \%$ and $8.9 \%$ in the manufacturer cost and retail price are expected, as seen in Fig. 6.

The sensitivity of the LCCA to the variation in the electricity price was also evaluated. Increasing elec- 
Fig. 6 Scenario results: LCC analysis



tricity prices by $10 \%$ would imply C2 MEPS corresponding to an average refrigerator energy consumption of $234 \mathrm{kWh} /$ year (improvement III in Fig. 6). Alternatively lowering the electricity price by $10 \%$ results in an average $\mathrm{C} 2$ energy consumption level of $276 \mathrm{kWh} /$ year (improvement I in Fig. 6). Analyzing the payback period enables the time it would take for consumers to earn a return on an investment in a more efficient refrigerator to be assessed.

Assuming a refrigerator lifetime of 16 years in Brazil $^{6}$, consumers would recover their investments under all the standard cases considered as the maximum payback period of 12 years for the most ambitious case of C5. Figure 7 shows the payback period in regard to the standards $\mathrm{C} 0, \mathrm{C} 1$, and so on. In summary, the payback analysis illustrates the trade-off and helps identify policies that will have net benefit for consumers (Wiel and McMahon 2001). The sensitivity analysis was also used to gain insights regarding the influence of electricity prices on the payback period. Considering set MEPS at the improvement level III in Fig. $6(+10 \%$ sensitivity), the corresponding payback is about 10.5 years, which is still lower than the average refrigerator's useful life expectancy.

\footnotetext{
${ }^{6}$ This is an assumption made by the authors based on life expectancy of appliances as reported in the $23 \mathrm{rd}$ annual portrait of the US appliance industry. The life expectancy for standard refrigerators is within the range of 10 to 18 years (MrAppliance 2003).
}

Suggested energy efficiency standards based on the LCCA results

Table 4 summarizes the results in terms of energy savings, payback period, and customer's electricity bill savings for two hypothetical standards regimes.

Under the first scenario, it is assumed that energy efficiency standards (MEPS) become effective in 2005 and savings are estimated for the 2005 to 2020 period. Remember that the MEPS aims to improve efficiency of the refrigerators belonging to all classes, i.e., A to $\mathrm{G}$ in the energy efficiency label (Fig. 2a). The results given in Table 4 show that the technical improvements in the refrigerator would save $46 \mathrm{TWh}$ of energy and R $\$ 8.49$ billion in the customer's electricity bill during the period of 16 years, from 2005 to 2020. It may be worth noticing that these standards were not implemented in 2005. Thus, anyone reading this paper could infer that these savings estimates are out of date, but it is not quite true due to the slow technical improvement in Brazilian refrigerators over time. The MEPS suggested in Fig. 6 of $266 \mathrm{kWh} /$ year is still lower than the energy consumption of a 2008 year refrigerator found in the retail market which is of $294 \mathrm{kWh} /$ year (adjusted volume of 314.61 - class A). The contrast between the energy consumption of a refrigerator in 2001 and 2008 may help to visualize the slow progress in the energy efficiency index of Brazilian refrigerators over time. For example, the energy consumption of the refrigerator found in Table 1 with adjusted volume of 3161 (net capacity of 272 and 311 , respectively, for the fresh food and frozen food 
Fig. 7 Estimated payback periods

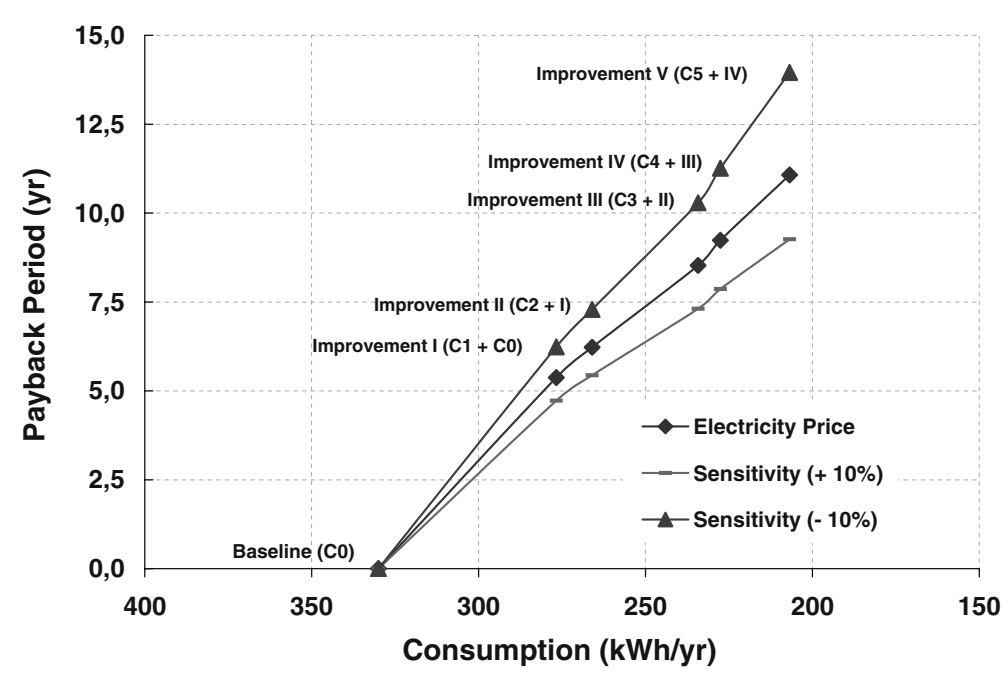

compartments) was $319 \mathrm{kWh} /$ year (26.6 kWh/month). In 2008, practically the same refrigerator was found in the retail market (net capacity of 272 and 30 l, respectively, for the fresh food and frozen food compartments), and the energy consumption was $294 \mathrm{kWh}$ /year (24.5 kWh/month; INMETRO 2008). This refrigerator was always of an A class level. As seen, the energy consumption of a class A refrigerator has decreased $7.8 \%$ in the period of 7 years, which is not very ambitious progress for the energy efficiency index. Furthermore, a striking discrepancy is noticed between the energy consumption of the European and the Brazilian models; for example, a European model $\left(267+35=3021-\mathrm{A}^{+}\right.$class $)$has an energy consumption of $237 \mathrm{kWh} /$ year (ENERGY+ 2008), whereas in Brazil, an equivalent model $(272+30=3021$ - same manufacturer-A class) demands $294 \mathrm{kWh} /$ year. It points toward a commercialized model $20 \%$ more efficient in Europe. These considerations still maintain that the estimates (MEPS in Fig. 6) are feasible.

For the second scenario, it is assumed that two energy efficiency standards are enforced, first in 2005 at the C2 level and another in 2010 at the C5 level, which takes into account all the higher energy efficiency design options considered in this analysis. The period of 16 years is computed from 2005 to 2020. The results given in Table 4 shows that in this scenario, 66 TWh of energy could be saved for corresponding $\mathrm{R} \$ 8.48$ billion in the customer's electricity bill. The customer's electricity saving are very close for both standards in Table 4. It is a noteworthy performance since, despite being the more energy-efficient refrigerator (66.68 TWh of energy savings), the refrigerator having all design options has a higher life cycle cost (as seen in Fig. 6). The electricity savings for the $24 \%$ standard and the $48 \%$ standard are, respectively, $\mathrm{R} \$ 11.63$ billion and $\mathrm{R} \$ 16.80$ billion (if not taking into account the life cycle cost).

Table 4 shows that refrigerators are expected to reach an average sale of 1.2 million units per year over the next 20 years in Brazil. This expectancy was taken into account in the estimation of the savings in Table 4. The sales rate was calculated using the linear

Table 4 Standards effective in 2005 (MEPS) and in 2010 (all design options): energy and economic impacts for the period from 2005 to 2020

\begin{tabular}{|c|c|c|}
\hline $\begin{array}{l}\text { Improved refrigerator energy efficiency } \\
\text { (compared to refrigerator features } \\
\text { of } 2000 \text { year) }\end{array}$ & $\begin{array}{l}24 \% \text { (standard from } 2005 \text { to } 2020 \text {; } \\
\text { design options } \mathrm{C} 0+\mathrm{C} 1+\mathrm{C} 2 \text { provided } \\
\text { in Table 2) }\end{array}$ & $\begin{array}{l}48 \% \text { (standard from } 2010 \text { to } 2020 \text {; design } \\
\text { option } \mathrm{C} 3+\mathrm{C} 4+\mathrm{C} 5 \text { added to standard } 2005 \text { ones) }\end{array}$ \\
\hline Payback period & 7 years & 12 years \\
\hline Energy savings & 46.18 TWh & $66.68 \mathrm{TWh}$ \\
\hline Saving in the customer's electricity bill & $\mathrm{R} \$ 8.49$ billions (US $\$ 2.57$ billions) & $\mathrm{R} \$ 8.48$ billions (US\$2.56 billions) \\
\hline
\end{tabular}


regression method based on the database of the last 12 years reported. This database is made available by Brazilian Institute of National Statistics and Geography (IBGE), which carries on an annual public program called National Research by Home Sampling (PNAD 2004).

\section{Environmental impacts}

In this paper, the environmental effects (or impacts) were also evaluated in terms of changes in emissions of pollutants such as carbon dioxide $\left(\mathrm{CO}_{2}\right)$ that would occur as a result of reduced energy consumption. The energy savings, as listed in Table 4, are typically converted to emission reductions using conversion factors (e.g., grams of emission per unit energy saved). Table 5 shows the reduction of 18.56 and 26.80 Mtons in emissions of carbon dioxide corresponding to the energy savings of 46.18 and 66.68 TWh, as pointed out in Table 4 .

The avoided emissions of $\mathrm{CO}_{2}$ may be traded in the global carbon credit market. Carbon credits are a key component of national and international emissions trading schemes that have been implemented to mitigate global warming. They provide a way to reduce greenhouse effect ${ }^{7}$ emissions on an industrial scale by capping total annual emissions and letting the market assign a monetary value to any shortfall through trading. Credits can be exchanged between businesses or bought and sold in international markets at the prevailing market price.

From the results in Table 5, it can be seen that $\mathrm{R} \$ 442.2$ million (US\$134 million) could be earned by capping $\mathrm{CO}_{2}$ emissions in the 16-year period of suggested MEPS. The carbon unit was quoted at US $\$ 5.00 / \mathrm{tCO}_{2}$ according to the variation of US\$5.50+ $50 \% / \mathrm{tCO}_{2}$ found in the literature (Haites 2004).

\section{Conversion factor for greenhouse gas ${ }^{8}$}

The emissions of $\mathrm{CO}_{2}$ listed in Table 5 were calculated from energy savings (Table 4) using a conversion factor of $\mathrm{EF}=0.402 \mathrm{tCO}_{2} / \mathrm{MWh}$. This

\footnotetext{
$\overline{7}$ The greenhouse effect is the process in which the emission of infrared radiation by the atmosphere warms a planet's surface.

${ }^{8}$ Greenhouse gases are the gases present in the atmosphere that reduce the loss of heat into space and therefore contribute to global temperatures through the greenhouse effect.
}

factor gives the grams or tons of emission per megawatt hour of energy saved. This emission factor is calculated according to the type of fuel used in the generation of electric power by a power plant (or generating station). In this paper, the emission factor was obtained for a natural gas combined cycle power plant (Natural Gas 2003). This is a thermal power plant that generates electric power from a gas turbine. Considerations in accordance with the guidelines of the National Greenhouse Gas Inventories Programme through the Intergovernmental Panel on Climate Change (IPCC) were used to calculate the emission factor (IPCC 1996). The aforementioned emission factor (EF) was calculated by:

$\mathrm{EF}=\frac{\mathrm{CEF} \times \mathrm{OCF} \times \frac{44}{12} \times \mathrm{SF}}{\eta}\left[\mathrm{tCO}_{2} / \mathrm{MWh}\right]$

where $\mathrm{CEF}=15.3$ is expressed in $\mathrm{tC} / \mathrm{TJ}$ (tons of $\mathrm{C} /$ terajoules; IPCC 1996). This is the carbon equivalent emission factor, which converts natural gas energy to net carbon emitted by the fuel burning process. OCF represents the fraction of carbon oxidized during the combustion, usually equal to 0.995 for natural gas (IUEP 2005). $\mathrm{SF}=0.0036$ is a scaling factor to convert energy units, expressed in terajoules, to electric units of megawatt hour (MWh). The symbol $\eta$ represents the thermal efficiency of natural gas combined cycle power plant, which is within the range of $47 \%$ to $56 \%$. In this work $\eta=50 \%$ was considered. Finally, the $44 / 12$ fraction converts greenhouse gases from an atomic weight basis (C) to full molecular weight $\left(\mathrm{CO}_{2}\right.$; IPCC 1996).

\section{Conclusion}

The analysis described in this article may give support and help discussions for establishment of MEPS for one-door refrigerators in Brazil. The summarized results represent important inputs to subsidy further discussion with manufacturers in the process of setting up efficiency standards and may be used as reference for organizations working to promote sustainable energy development.

It is shown that the Brazilian refrigerator can be technically improved, allowing significant savings of electricity consumption in Brazilian households.

From LCC analysis, the increase of $11.44 \%$ in the refrigerator retail price is expected for a standard 
Table 5 Standards effective in 2005 (MEPS) and in 2010 (all design options): environmental impacts for the period from 2005 to 2020

\begin{tabular}{lll}
\hline $\begin{array}{l}\text { Improved refrigerator } \\
\text { energy efficiency }\end{array}$ & $\begin{array}{l}24 \% \text { (from } 2005 \text { to 2020; design options } \\
\mathrm{C} 0+\mathrm{C} 1+\mathrm{C} 2 \text { provided in Table } 2)\end{array}$ & $\begin{array}{l}\text { 48\% (from 2010 to 2020; design option } \\
\mathrm{C} 3+\mathrm{C} 4+\mathrm{C} 5 \text { added to standard 2005 ones) }\end{array}$ \\
\hline $\begin{array}{l}\text { Emissions of carbon dioxide }\left(\mathrm{CO}_{2}\right) \\
\text { Carbon credit market }\end{array}$ & $\begin{array}{l}18.56 \text { Mtons } \\
\mathrm{R} \$ 306.24 \text { millions (US\$92.80 millions) }\end{array}$ & $\begin{array}{l}26.80 \text { Mtons } \\
\mathrm{R} \$ 442.2 \text { millions (US\$134 millions) }\end{array}$ \\
\hline
\end{tabular}

establishment of $24 \%$ higher efficiency from 2005 to 2020 and a corresponding payback of 7 years. It also represents R $\$ 8.49$ billion (US $\$ 2.57$ billion) of savings in the customer's electricity bill. It is a noteworthy result for Brazil, since the estimated 46.18 TWh of saved energy is the equivalent of the operation of 35 Brazilian natural gas thermoelectric power plants during 6 months. Moreover, results show that $\mathrm{R} \$ 306.24$ million (US\$92.80 million) can be earned in the carbon market by capping $\mathrm{CO}_{2}$ emissions in 18.56 megatons.

Finally, if strict MEPS are enforced (48\% in Table 4) during the period from 2010 to 2020, the results are $44.44 \%$ more attractive with regard to energy savings, avoided $\mathrm{CO}_{2}$ emissions, and carbon market trading.

Acknowledgments The authors would like to thank the International Energy Agency/Climate Technology Initiative (IEA/CTI), the International Energy Initiative (IEI), the Environmental Protection Agency (EPA), and the São Paulo Research Council (FAPESP) for their financial support.

\section{Appendix 1}

This appendix is provided for background purposes and is based on the CLASP_Energy-Efficiency Labels and Standards: A Guidebook for Appliances, Equipment, and Lighting (Wiel and McMahon 2001). It is a EU analysis done in 1993. However, a more complete and up-to-date one done in 2001 (the "Cold II" study) is available and should be preferred (Waide 2001).

\section{Energy efficiency standards}

Three types of energy efficiency standards are described in the CLASP-Energy-Efficiency Labels and Standards: A Guidebook for Appliances, Equipment, and Lighting (Wiel and McMahon 2001): prescriptive standards, minimum energy performance standards (MEPS), and class average standards, any of which could be either mandatory or voluntary.
- Performance standards prescribe minimum efficiencies (or maximum energy consumption) that manufacturers must achieve in all products manufactured after a certain date. These standards specify the energy performance, but not the technology or design specifications of the energyefficient product.

The two most widely used analytical approaches for standards setting are: statistical analysis of current products and engineering/economic analysis of future possibilities. These approaches, and others, can be used in combination and are not mutually exclusive.

Statistical approach

Figure 8 shows a statistical analysis performed by the Group for Efficient Appliances (GEA) for three-star refrigerator-freezer models available in EU countries. Four lines are shown in this figure; they represent the average energy use obtained through a regression analysis of all of the data points, a $10 \%$ energy savings line, a $15 \%$ energy savings line, and a longterm standards line. ${ }^{9}$ After the regression line is calculated, the least energy-efficient model is found and replaced with a model of higher efficiency. The number of models stays constant. The energy savings for the higher efficiency model is calculated, and energy savings are aggregated until the total reaches the goal $(10 \%, 15 \%$, etc.). Then, the resulting data points are used to derive a new regression line.

Economic/engineering approach

An engineering analysis is first carried out for each product class within a product type to estimate manufacturing costs for improving efficiency compared to a baseline model. Installation and mainte-

\footnotetext{
${ }^{9}$ The fourth line was obtained through an engineering/ economic approach.
} 
Fig. 8 Statistical approach as applied to European Union refrigerator-freezers



nance costs are also calculated. The engineering analysis can be described in seven steps: (1) select appliance classes; (2) select baseline units; (3) select design options for each class; (4) calculate efficiency improvement for each design option; (5) combine design options and calculate efficiency improvements; (6) develop cost estimates (include installation and maintenance) for each design option; (7) generate cost efficiency curves.
The expected costs of manufacturing, installing, and maintaining each design option must be estimated, including the ability of the after-market service sector to effectively maintain the performance of high efficiency equipment. In some cases, manufacturer costs are very difficult to obtain and it may be necessary to go directly to retail prices; this is a feasible approach if all the designs under consideration already exist in the marketplace.
Fig. 9 LCC analysis results for two sets of US standards for a top-mount, autodefrost refrigerator-freezer (Wiel and McMahon 2001)

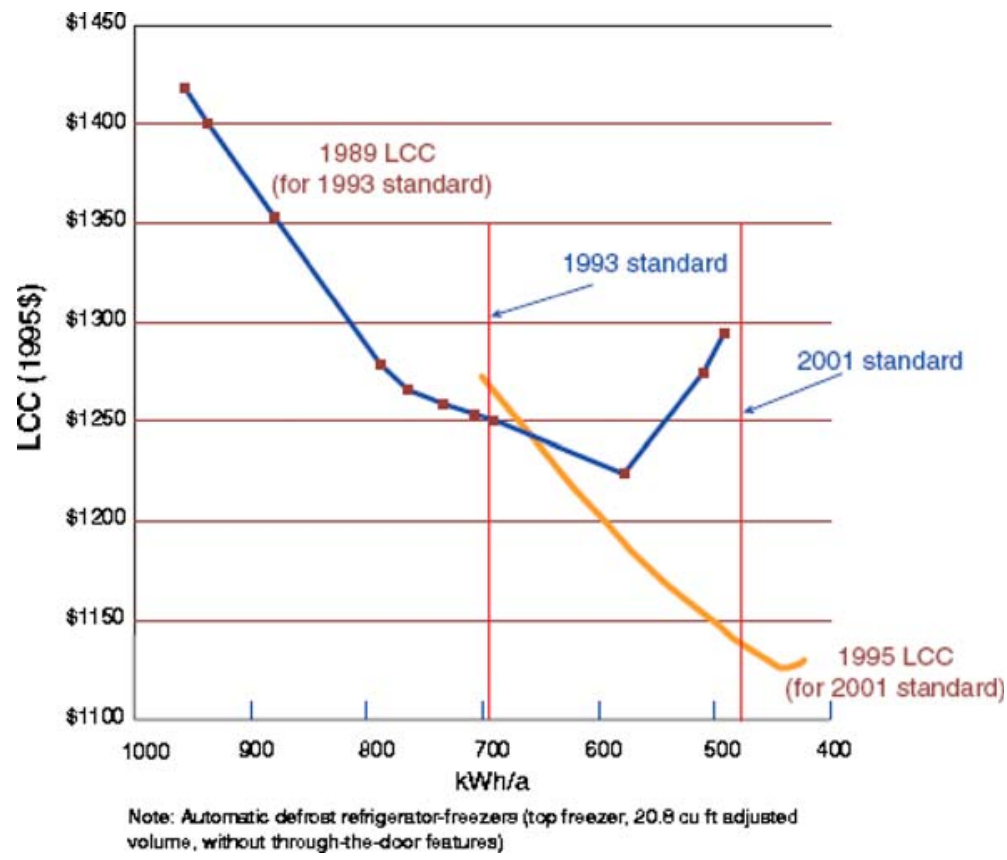




\section{Energy efficiency standard in North America}

Once the engineering analysis is complete, it is customary to analyze the economic impact of potential efficiency improvements on consumers by analyzing consumer payback period and LCC. Figure 9 shows the LCC analysis results for two sets of US standards for a top-mount, auto-defrost refrigerator-freezer.

The minimum LCC (where the consumer receives the most benefit) occurs around $450 \mathrm{kWh} /$ annum. The minimum LCC is not always chosen for a new standard because many other factors must be considered. For instance, options below $470 \mathrm{kWh} /$ annum were rejected for use in a proposed standard because increased insulation thickness would make these refrigerators too wide to fit into fixed spaces in some existing kitchens, assuming that internal volume remains constant as insulation thickness increases.

\section{References}

3CEE Report (2006). The 3 Country Energy Efficiency ProjectUnited Nations Environment Programme-UNEP. Developing Financial Intermediation Mechanisms for Energy Efficiency Projects in Brazil, China and India. Brazil Country Report. 2006 (see also http://www.3 countryee.org/reports.htm).

ANEEL. (2002a). Brazilian Electricity Regulatory Agency. Tariff rates in use. See also www.aneel.gov.br/341.htm.

ANEEL. (2002b). Brazilian Electricity Regulatory Agency. Discount Rate. (n. d.). Retrieved in 2002 from http://www. aneel.gov.br/cedoc/res2002492.pdf.

BEN. (2004). National Energetic Balance (Balanço Energético Nacional). Mines and Energy Ministry. (n. d.). Retrieved 2004 from http://www.mme.gov.br/site/menu/select main menu item.do?channelId=1432\&pageId=1589.

Biermayer (2001). Life-cycle cost analysis: Refrigerators. Buenos Aires: Ernest Orlando Lawrence Berkeley National Laboratory (LBNL), IRAM, (March 2001).

Brazilian Law no. 10.295. (2001). National Energy Conservation Policy and Rational Use of Energy (Dispõe sobre a Política Nacional de Conservação e Uso Racional de Energia e dá outras providências). Federal Senate Decree no. 4059 of 10/ 17/2001. Regulated law of 12/19/2001.

Chade, J. F. (2004) Electric energy management as seen by consumers and energy distributors (Estudos do Sistema de Gerenciamento pelo Lado da Demanda para Consumidores e Distribuidores de Energia Elétrica). In Proceeding of XVI National Symposium of Electric Energy Distributors. (XVI Seminário Nacional de Distribuidores de Energia ElétricaSENDI). Brasília. Brazil. 2004. no. 583 (in Portuguese).

CLASP (2003). Commission Directive 2003/66/EC. Energy labeling of household electric refrigerators, freezers and their combinations. Collaborative Labeling and Appliance
Standards Program. (n. d.). Retrieved 2003 from http:// www.clasponline.org/disdoc.php?no=72.

Datamark. (2002). Sao Paulo, Brazil. See also: http://www. datamark.com.br.

DOE. (1995). Technical Support Document: Energy Efficiency Standards for consumer products: Refrigerators, RefrigeratorsFreezers, \& Freezers. US Department of Energy, 391 pp., July 1995.

Embraco. (2002). Brazilian Compressor Company. Learn how a refrigeration system works. (n. d.). Retrieved 2002 from http://www.embraco.com/ingles/familia_vcc.htm.

ENERGY+. (2002). Europe's most energy-efficient refrigerators \& freezers. (n. d.). Retrieved 2002 from http://www.energy-plus. org/english/products/available/product_sheet?rid=661332625.

ENERGY+. (2008). Find the most energy-efficient appliance which fits your needs. 2008 (see also http://www.energyplus.org/english/products/available/.

Haites, E. (2004). Estimating the market potential for the clean development mechanism: Review of models and lessons learned. IEA-International Energy Agency, PCFplus Report 19, Washington DC, 2004, 102 pages. See also http://www.iea.org/textbase/papers/2004/cdm.pdf.

Hakim, S. H., Turiel, I. (2002). Cost-efficiency analysis in support of the energy conservation standards for refrigerator/ freezers. Energy Efficiency Standards Activity. See also http://eappc76.1bl.gov/tmacal/ees.cfm.

PNAD. (2004). Brazilian Institute of National Statistics and Geography (IBGE). National Research by Home Sampling (PNAD). http://www.ibge.gov.br/home/estatistica/ populacao/trabalhoerendimento/pnad2004/default.shtm

INMETRO. (2002). National Institute of Metrology, Standards and Industry Quality (Instituto Nacional de Metrologia, Normalização e Qualidade Industrial). See also www.inmetro.gov.br/ consumidor/prodEtiquetados.asp\#pbe (in Portuguese).

INMETRO. (2008). National Institute of Metrology, Standards and Industry Quality-INMETRO. 2008. See also www.inmetro. gov.br/consumidor/pbe/refrigeradores.pdf (in Portuguese).

IPCC. (1996). Intergovernmental Panel on Climate Change/National Greenhouse Gas Inventories Programme (IPCC/NGGIP). Revised 1996 IPCC Guidelines for National Greenhouse Gas Inventories: Workbook (Volume 2). See also http://www.ipccnggip.iges.or.jp/public/gl/guidelin/ch1wb1.pdf.

ISO 7371. (1995). Household refrigerating appliances - Refrigerators with or without low-temperature compartment - Characteristics and tests methods. ISO - International Organization for Standardization.

IUEP. (2005). Common conversion factors. International Utility Efficiency Partnerships, Inc. (IUEP). (n. d.). Retrieved 2005 from http://www.ji.org/RFP2005/CommonConversion Factors.htm.

Merrian, Verone, Feng. (2002). EPA refrigerator Analysis (ERA) program: User's manual, version 1.2E. Cambridge, Massachusetts. Arthur D. Little, Inc.

MrAppliance. (2003). Expert Appliance Repair. Life expectancy of appliances-23rd annual portrait of the US appliance industry. See also http:/www.mrappliance.com/expert/ appliance_guide.aspx.

Natural Gas Website (2003). (n. d.) Retrieved 2003 from http:// www.gasnet.com.br/gasnet_br/termeletricas/ciclo.asp.

PROCEL (2002a). National Energy Conservation Program (Programa Nacional de Conservação de Energia Elétrica). 
Energy Consumption Catalogue. (n. d.). Retrieved 2002

from http://www.eletrobras.gov.br/procel/site/seloprocel/ equipamentoscomselo_948.asp.

PROCEL (2002b). National Energy Conservation Program (Programa Nacional de Conservação de Energia Elétrica). Brazilian Energy Efficiency and Endorsement Labels. (n. d.). Retrieved 2002 from http://www.eletrobras.com/ procel/site/seloprocel/apresentacao.asp.

Vendrusculo, E. A., Queiroz, G. C., Jannuzzi, G. M., Mendes, N., Borges, T., Pomilio, J. A. (2003). "Technical improvement of residential refrigerator in Brazil: Energy efficiency analysis". In: 3rd International Conference on Energy Efficiency in Domestic Appliances and Lighting (EEDAL'03) Turin, Italy. 2003.

Waide, P. (2001). Findings of the Cold-II SAVE study to revise cold appliances energy labeling and standards in the EU, ECEEE Summer Study, Mandelieu, June 2001, paper no. 5,175. Available from www.eceee.org.

Wiel, S., McMahon, J. E. (2001). The S\&L guidebook-Energyefficiency labels and standards: A guidebook for appliances, equipment, and lighting. Collaborative Labeling and Appliance Standards Program (CLASP). See also http://clasponline.org/ standard-label/toolkit/guidebook/index.php3. 